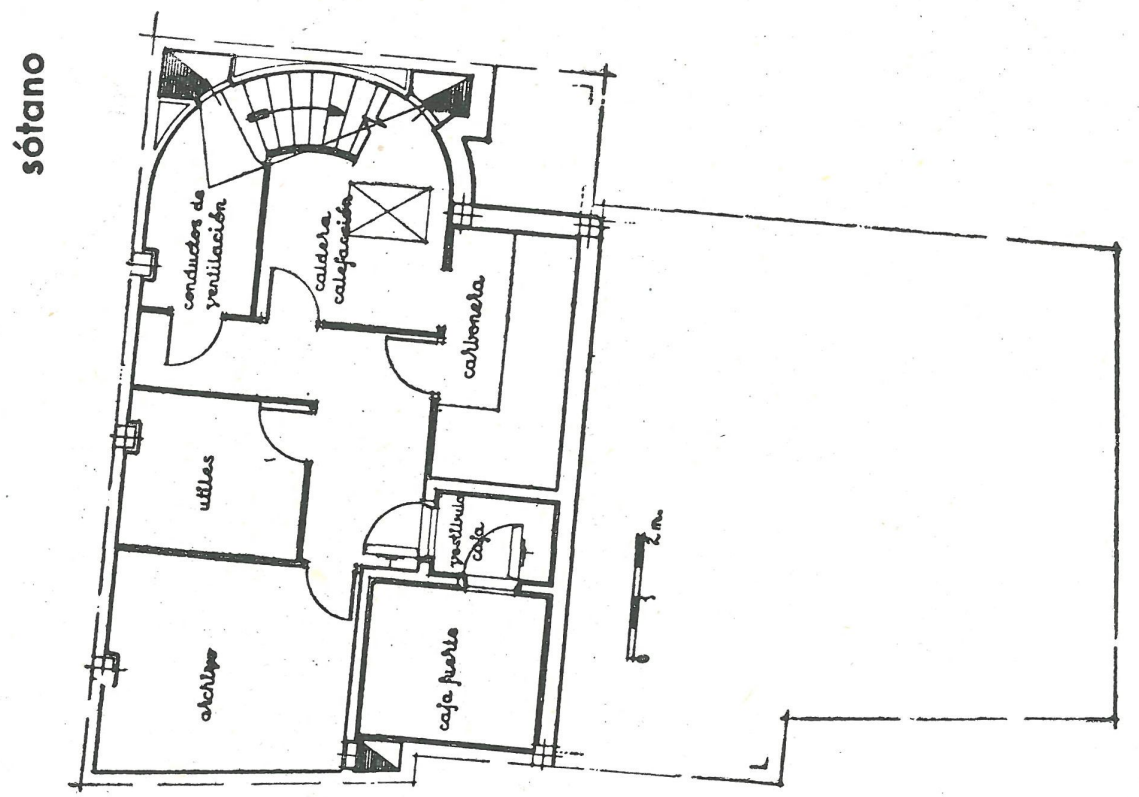

$145 \cdot 43$

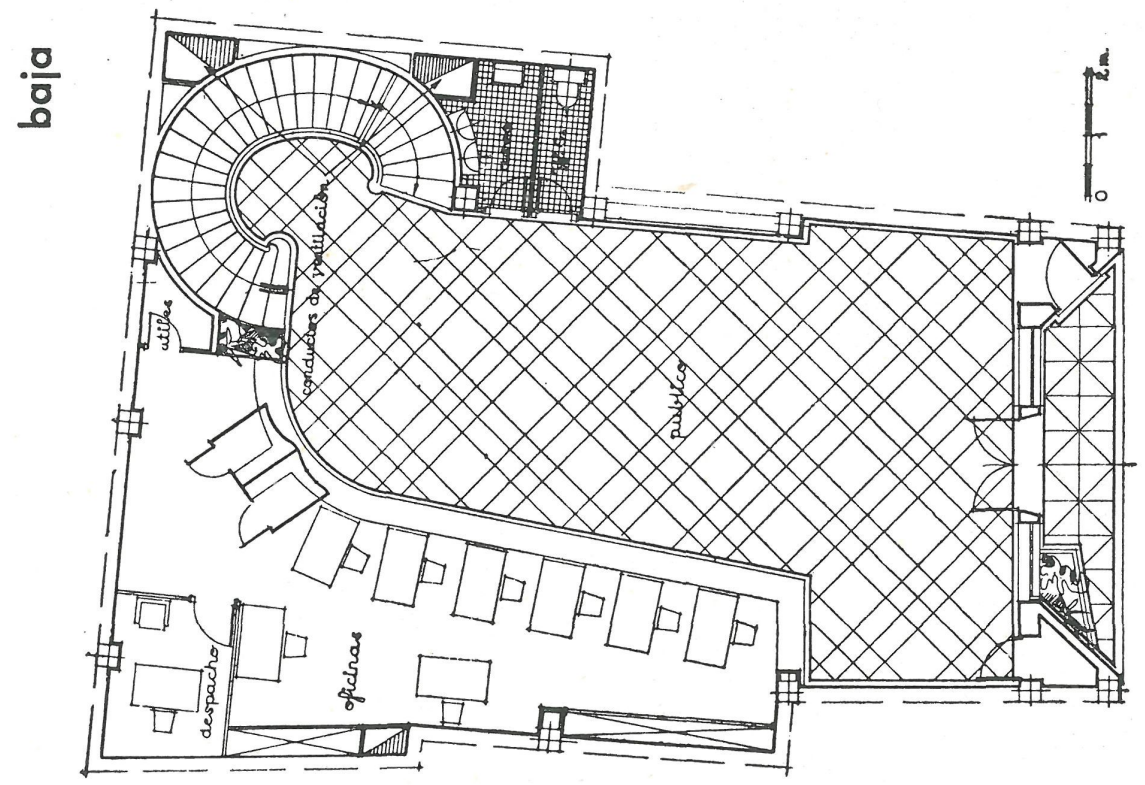

\title{
banco rural y mediterráneo Sevilla
}

A. DE LA PEÑA NEILA, arquitecto

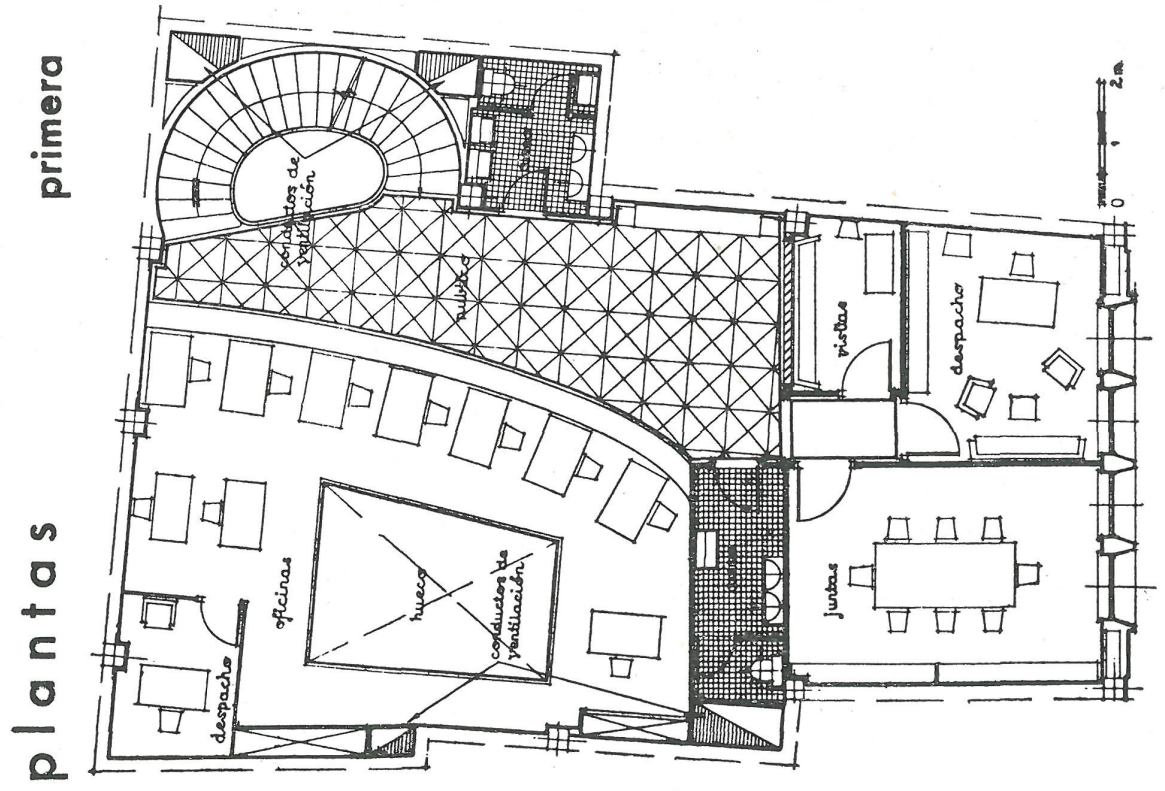

Su construcción, en el núcleo comercial de la ciudad -en la calle de la Cerrajería, junto a la de Sierpes-, rodeado de edificios de las más variadas características y estilos, presentaba tres aspectos fundamentales a resolver:

a) el componer una fachada moderna, pero sin estridencias irreflexivas, de modo que no fuera un "grito" llamativo,

junto a las casas circundantes, y conservara la dignidad y empaque que requiere el fin a que se destina; b) la brevedad de plazo - cinco mesesen que se debía realizar la construcción, obstacularizada por la circunstancia de su emplazamiento en una zona. de comercio, con restricción de horas para el tráfico rodado; c) la dificultad que ofrecía el firme de ínflma calidad, constituído por terrenos de aluvión.

La distribución, en tres plantas y un sótano, es la tradicional y lógica del género: oficinas amplias, despachos, salón de juntas, despacho del director, sala de visitas y aseos.

INFORMES DE LA CONSTRUCCION 97 

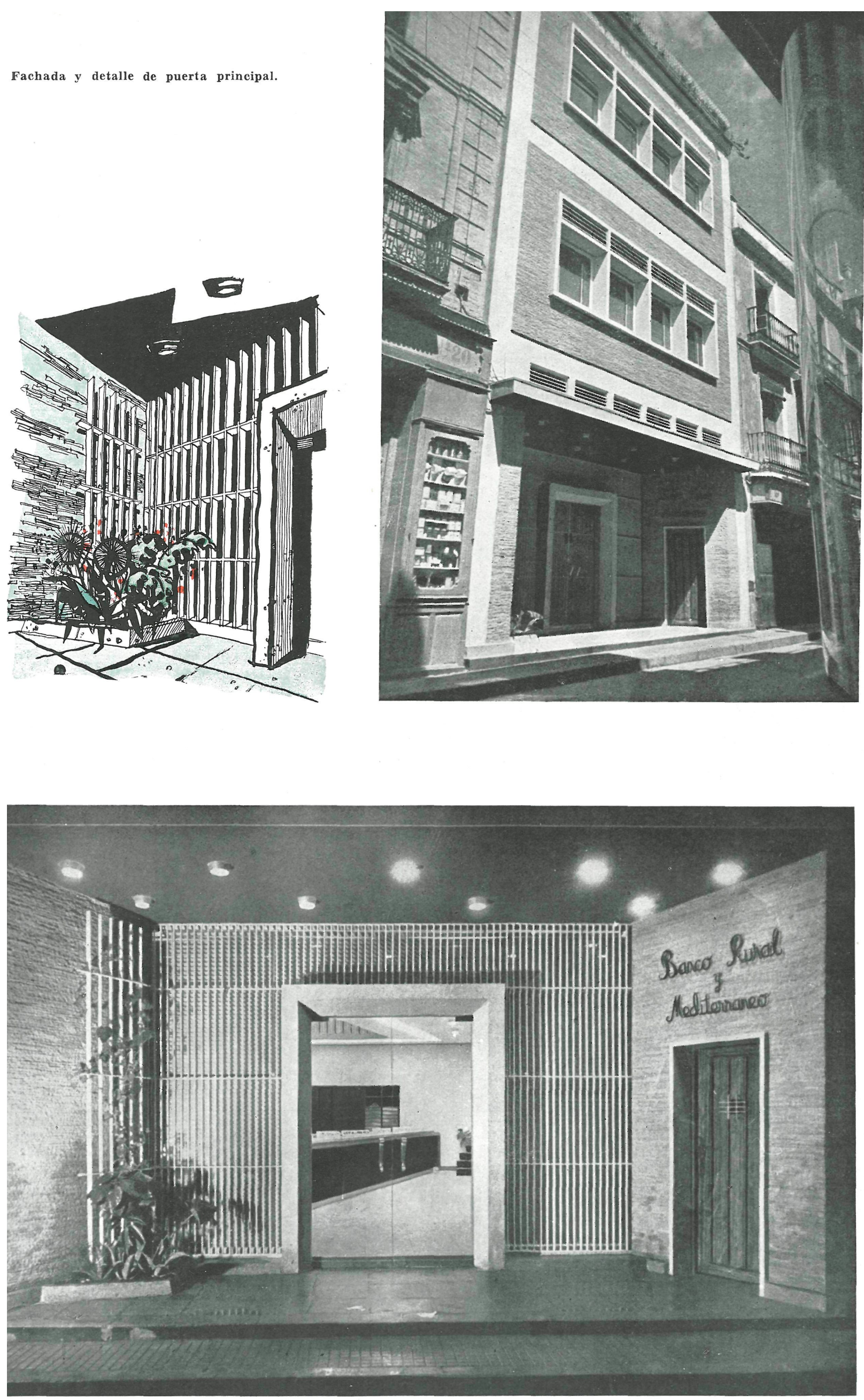

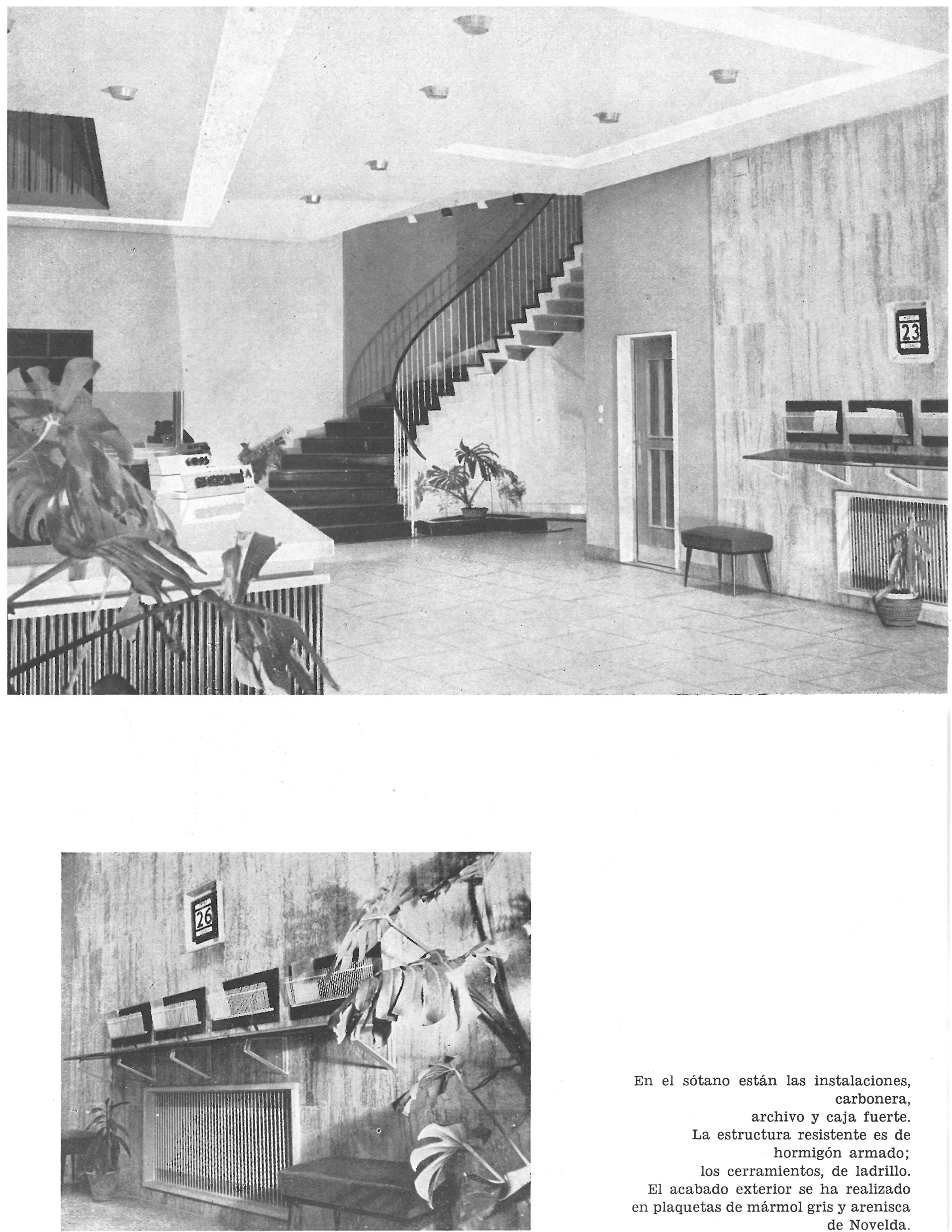

En el sótano están las instalaciones,

carbonera,

archivo y caja fuerte.

La estructura resistente es de

hormigón armado;

los cerramientos, de ladrillo.

El acabado exterior se ha realizado

en plaquetas de mármol gris y arenisca de Novelda. 


\section{hall principal}

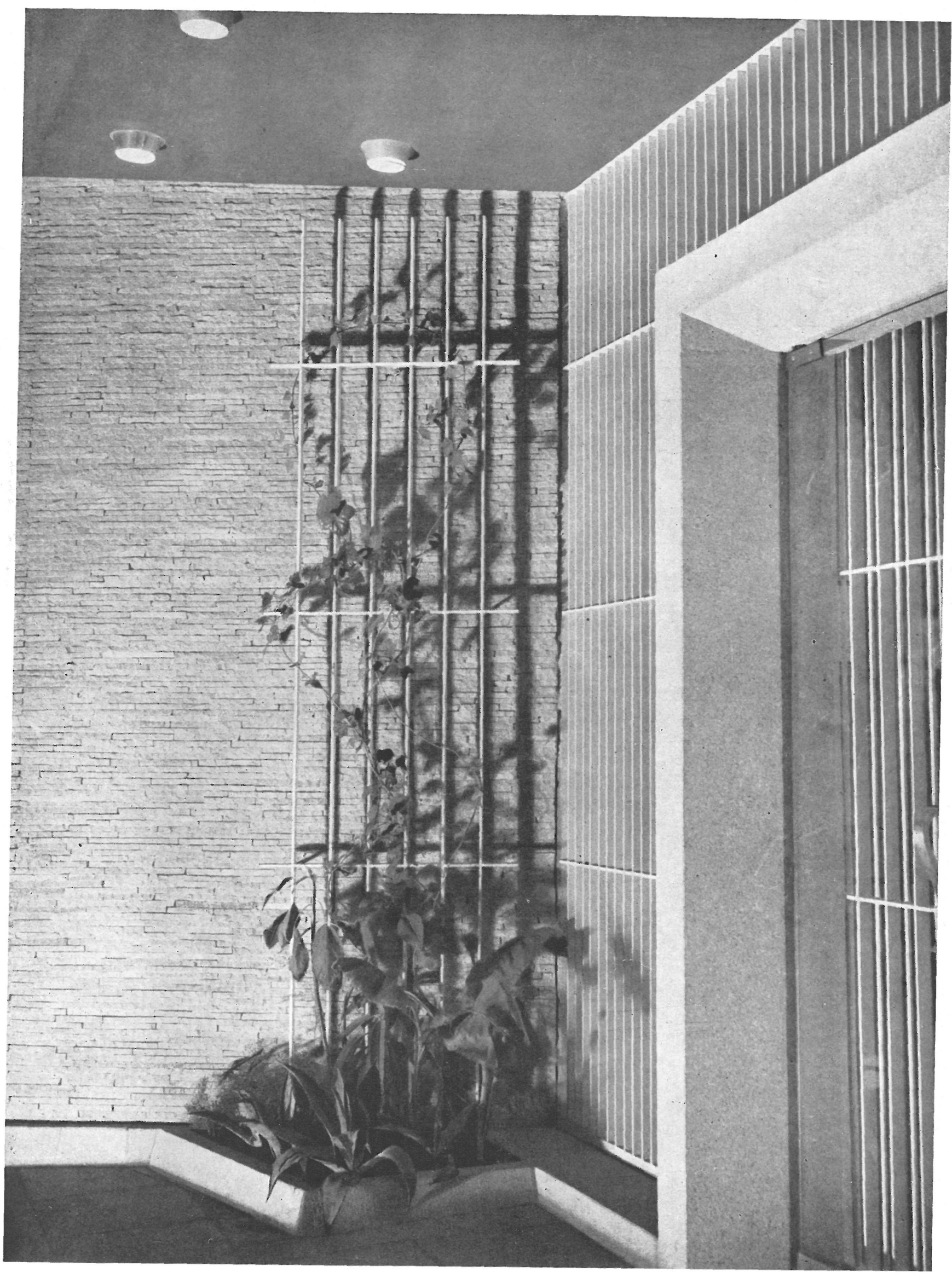



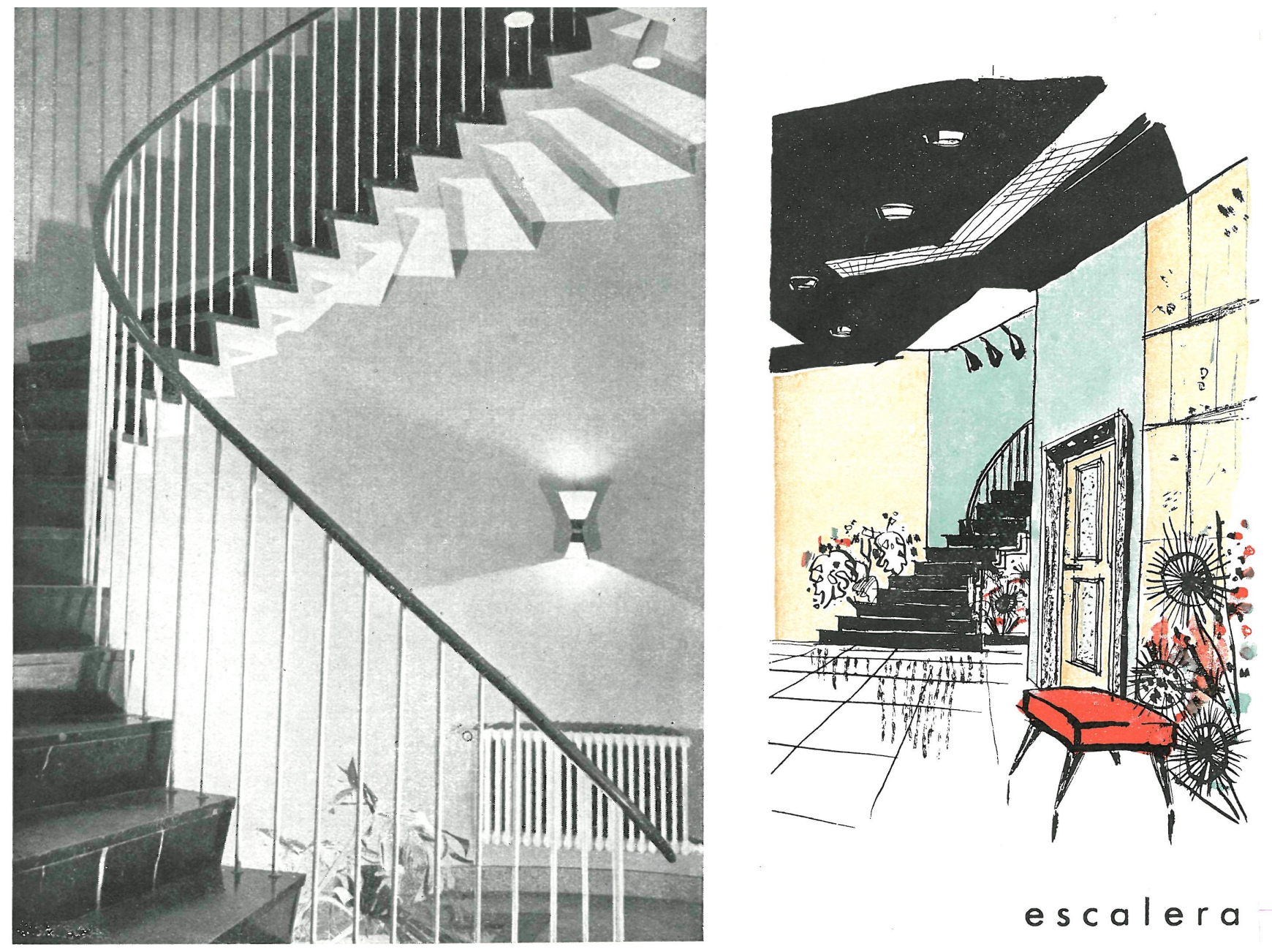

escalera

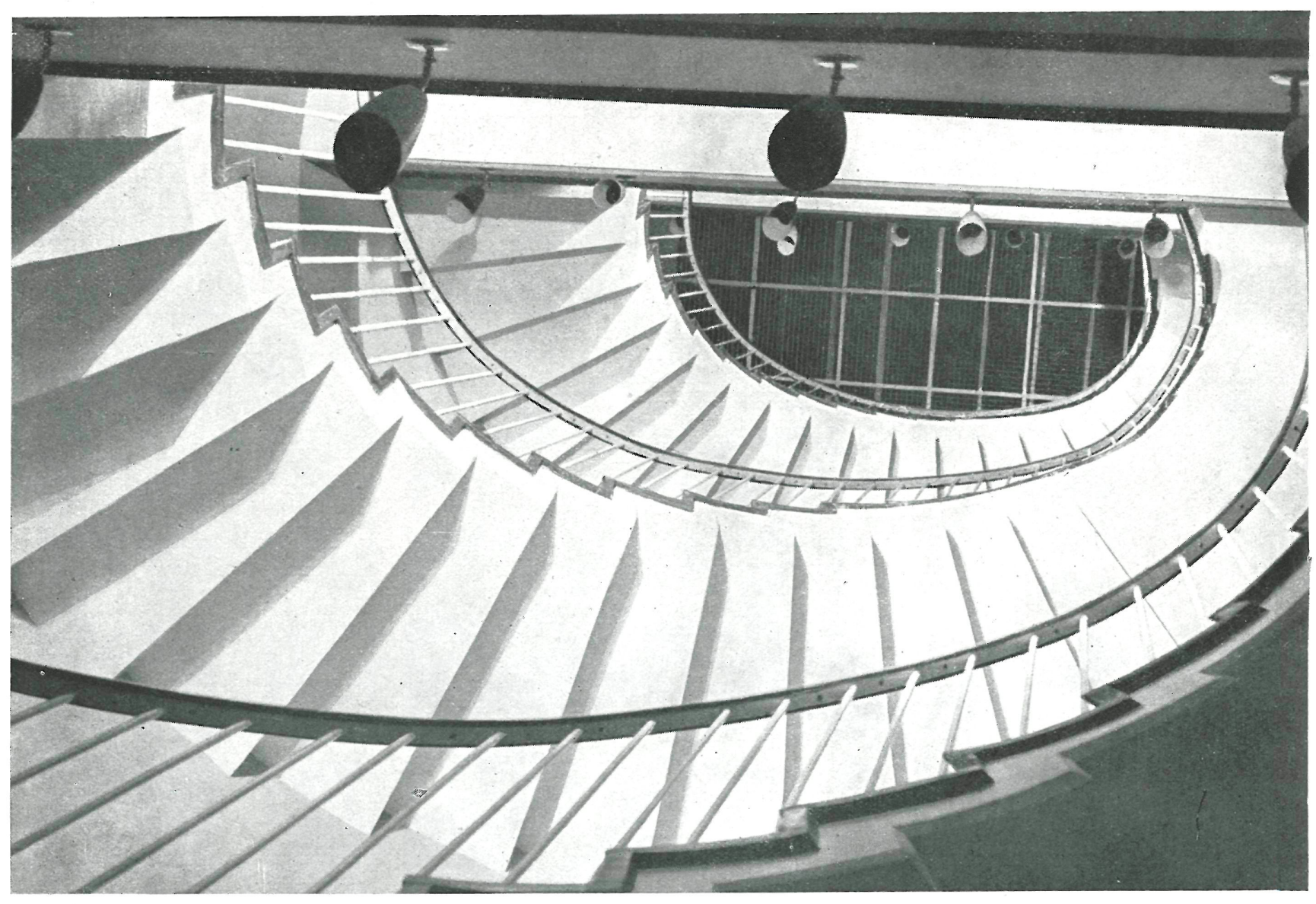




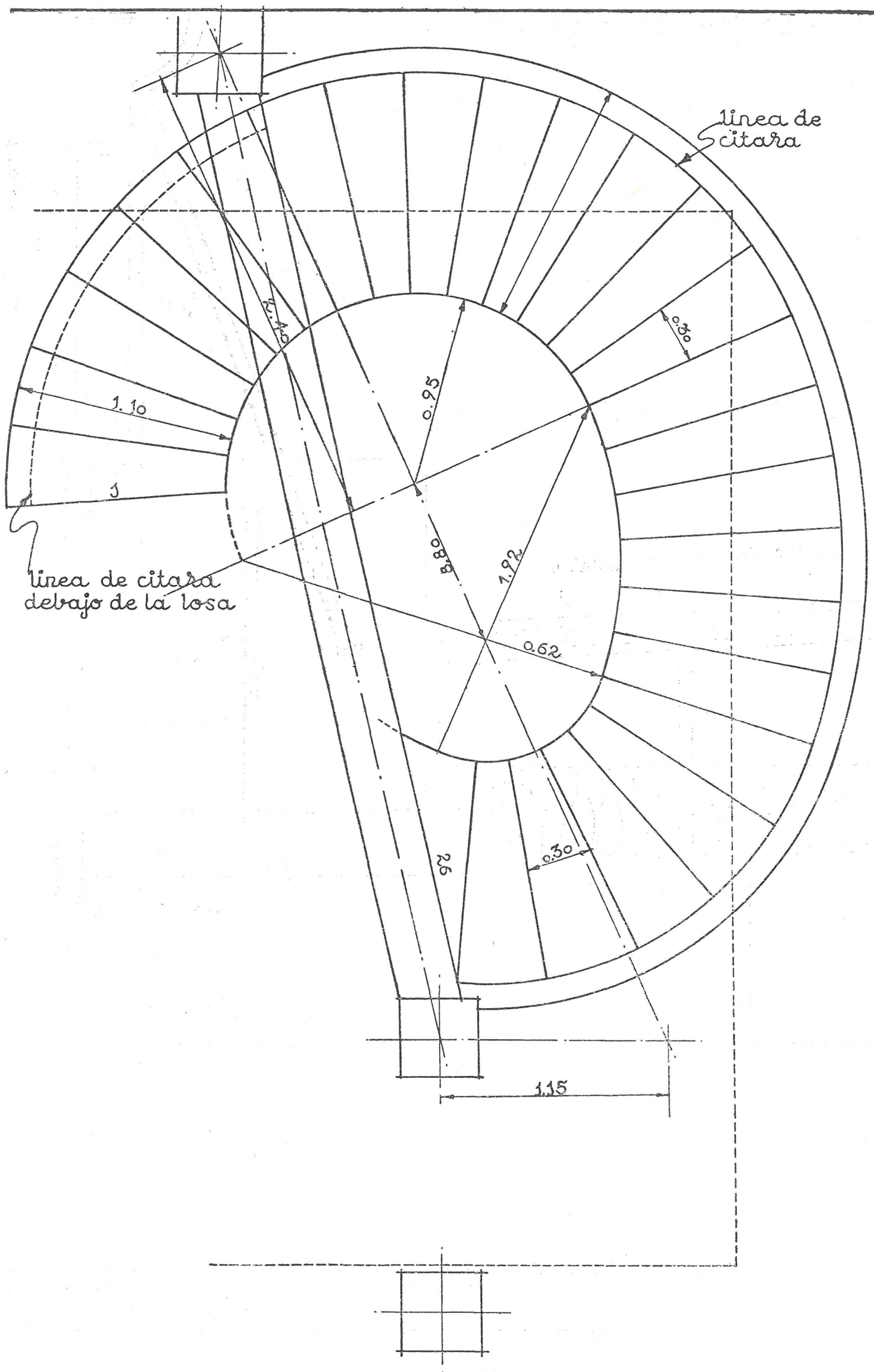

planta de escalera 


\section{barandilla de coronación de fachada}

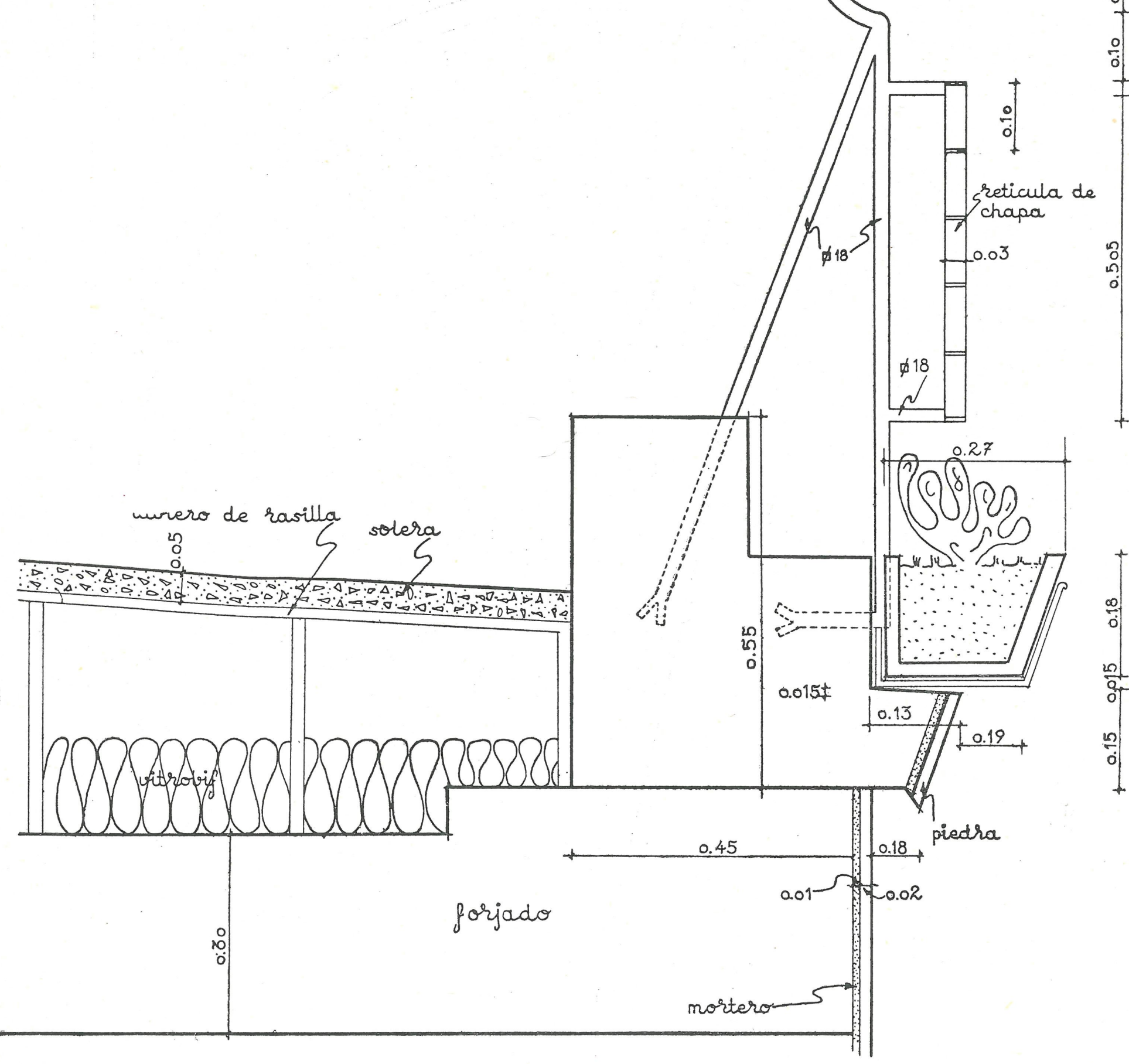

La decoración interior es rica, sencilla y elegante, amenizada con un mobiliario alegre y un tipo de mostrador, en madera, que se aparta de la rigidez clásica, árida y fría, de los establecimientos bancarios. De vez en cuando, en rincones adecuados la mancha verde y llena de vida de una planta nos da a entender un afán de comunicación con la naturaleza, aun en el centro de una gran urbe y dentro de un local burocrático. 


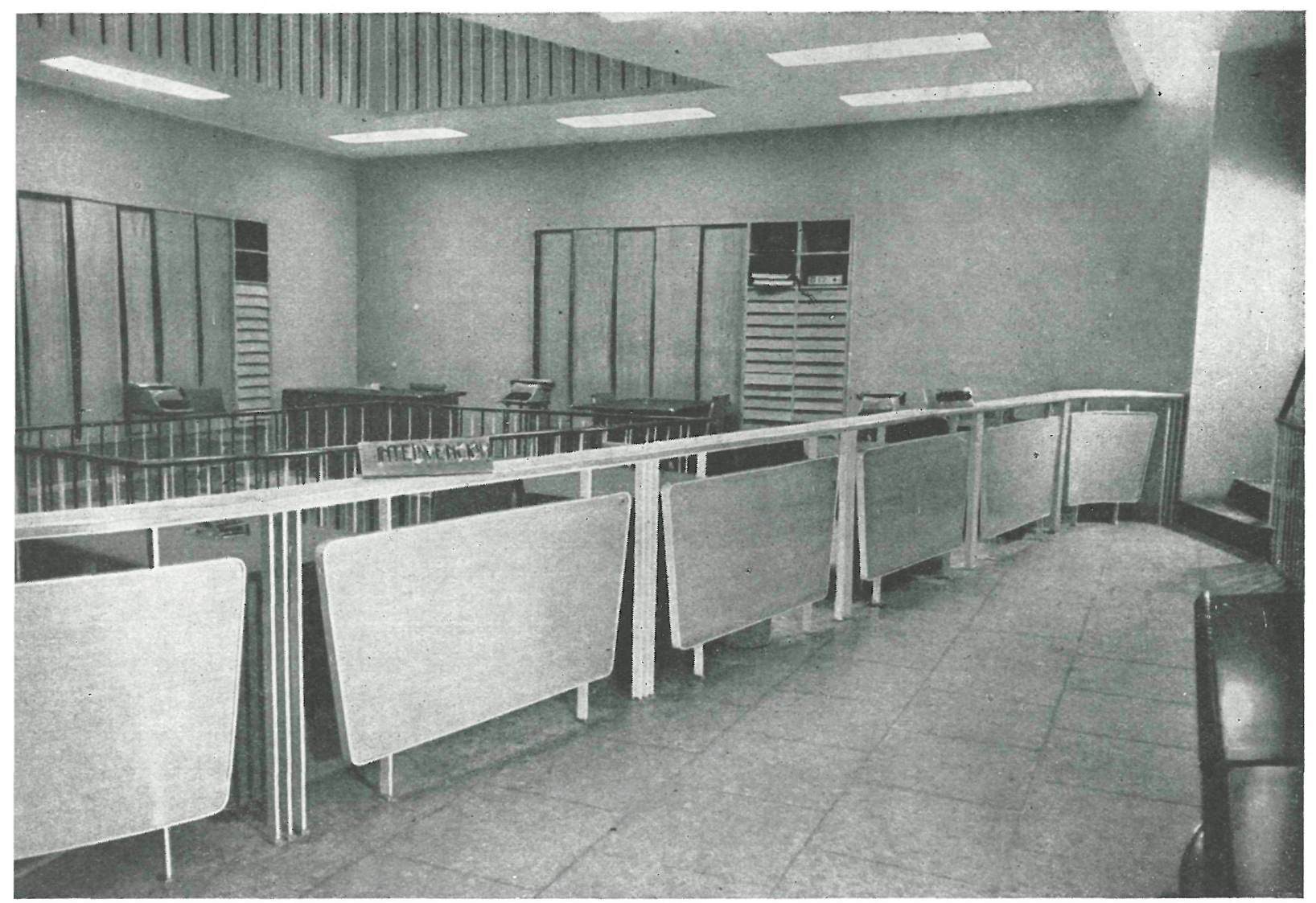

Vista general y trador.

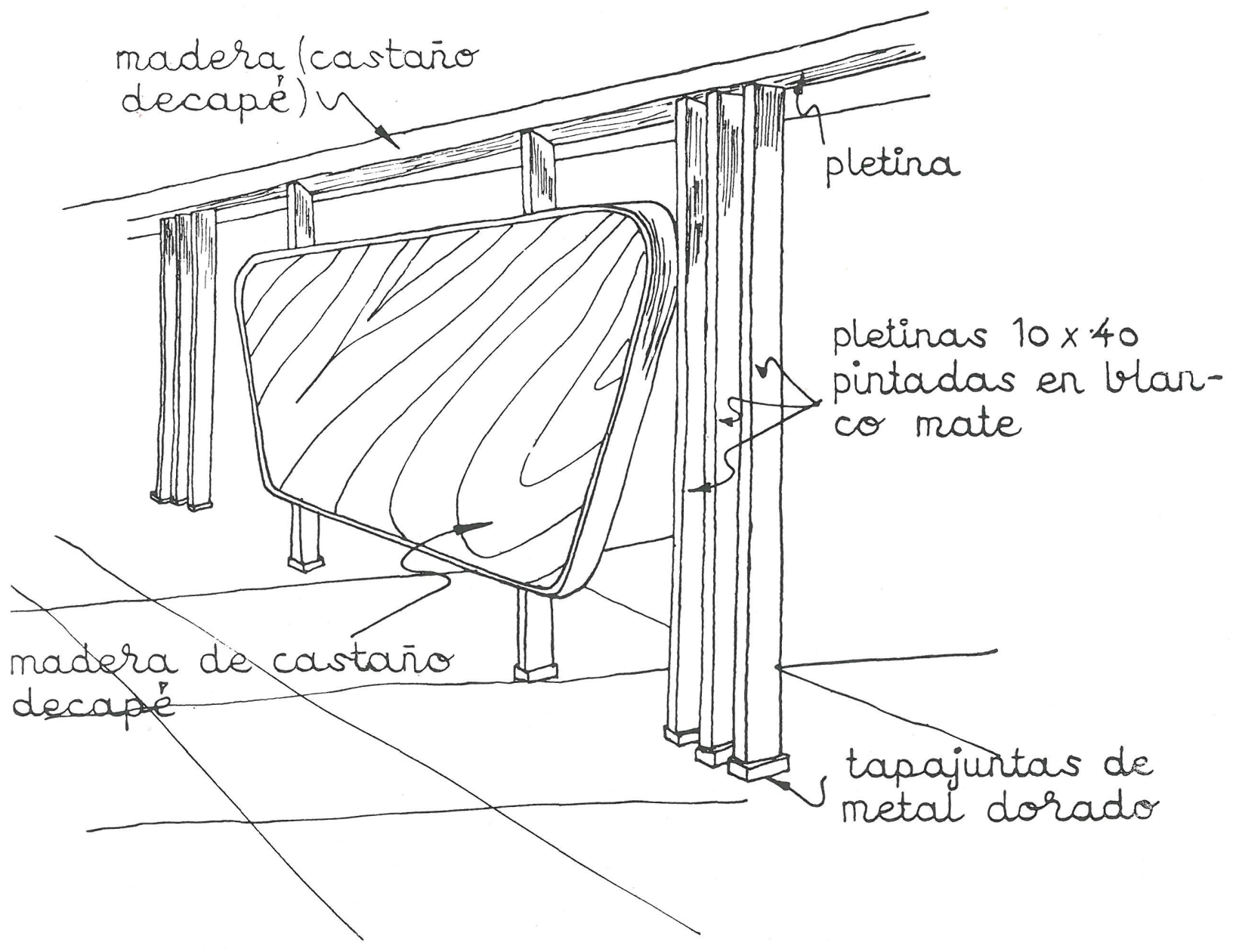




\section{dirección}

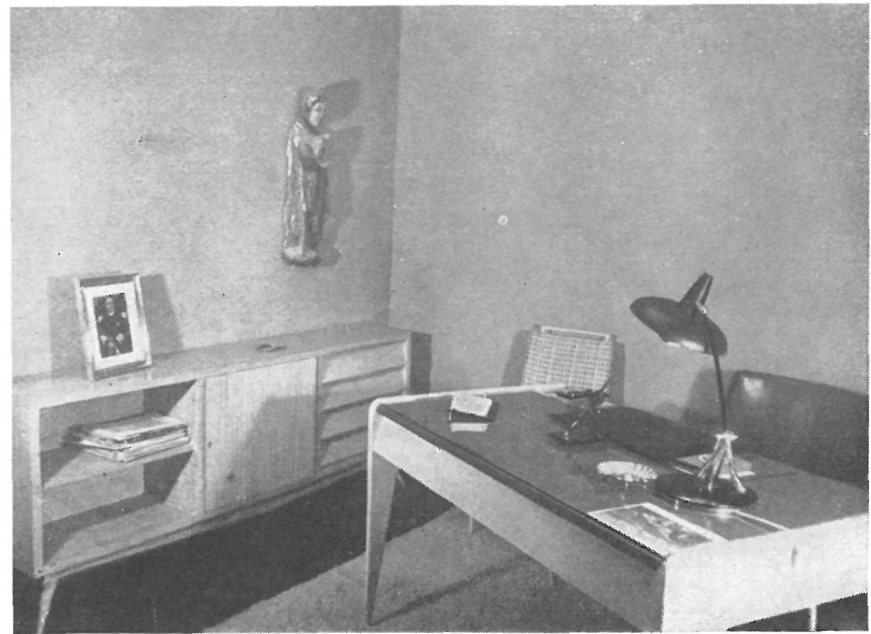

Igualmente existe el intento de alegrar el edificio, en su aspecto exterior, mediante las rejas blancas, el pequeño porche y una jardinera festiva; elementos todos de sencilla factura y de acuerdo con las directrices modernas de la arquitectura de nuestro tiempo.

La propia escalera helicoidal es una nota destacada por sus ritmos de líneas ascendentes, que constituyen un elemento de acusada fuerza decorativa.

Fotos: ARJONA
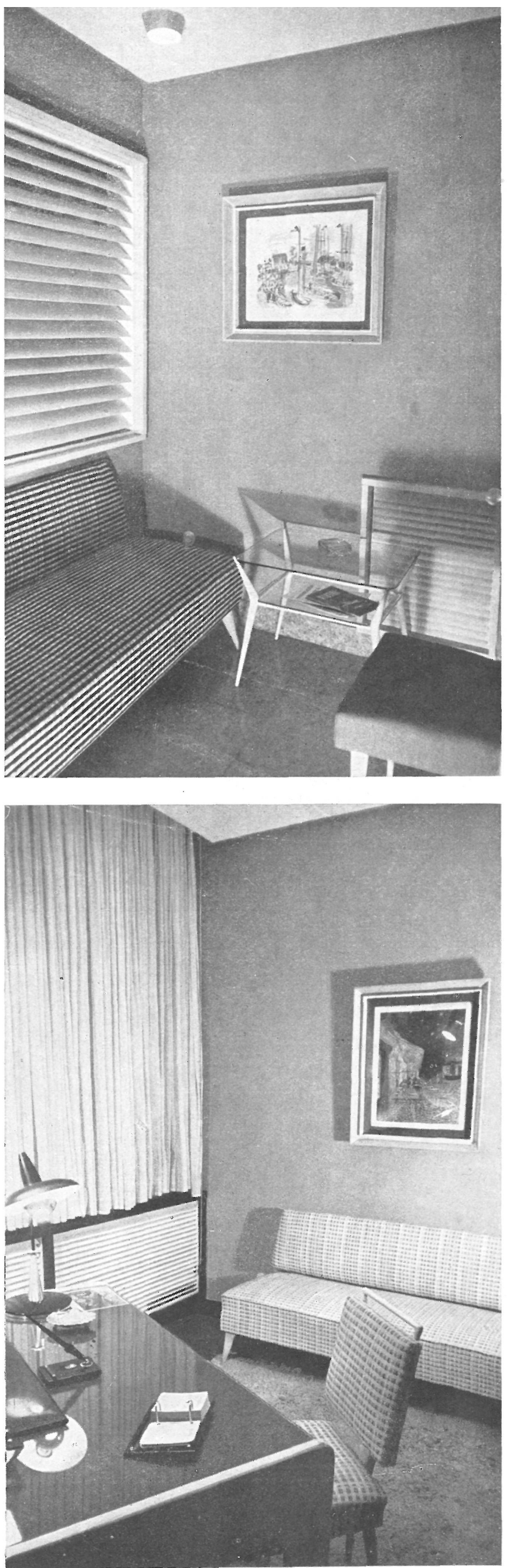